\title{
Effect of Organizational Capital on Cost Stickiness at Indonesian Manufacturing Companies
}

\author{
Meriza Saguliannita ${ }^{*}$, Christina Juliana \\ Faculty of Economics and Business, Universitas Indonesia, Jakarta, Indonesia \\ *Corresponding author.Email: mrza_sglnt@yahoo.com
}

\begin{abstract}
This study analyzes the phenomenon of cost stickiness (CS) by considering the impact of the level of organizational capital (OC) on sales, general, and administration (SG\&A) expenses. OC reflects technologies and business processes that allow companies to optimize resources better than other companies. Costs associated with organizational development are mostly SG\&A. CS is an asymmetric cost behavior related to sales activity, caused by the resourceadjustment decisions made by management. The uncertainty of market demand influences the level of sales, such that it affects resource management and earnings performance. This research performs empirical tests on financial data of manufacturing companies listed in the Indonesian Stock Exchange (IDX) from 2010-2016. For extended CS analysis, we also use quarterly financial statement data. We find from global samples that manufacturing companies in Indonesia show anti CS behavior. In the High-OC category, using the annual data sample, the quintile (median) group showed anti-CS (CS) behavior. Meanwhile, in the Low-OC category, the annual data showed anti-CS for the quintile (median) group. In the High- (Low-) OC category, the quarterly data sample showed CS (anti-CS). This study provides insights for evaluating management behavior when managing costs and financial impacts of OC in a manufacturing company's financial performance.
\end{abstract}

Keywords: cost stickiness, cost behavior, organizational capital, intangible investment

\section{INTRODUCTION}

Intangible capital is a modern business and economic term that describes sources of future benefits that have no physical form (Miyagawa \& Kim 2008; Lev et al. 2005). However, the value added from intangible capital is not always reflected in company financial statements. As the key indicator of the company's commitment to intangible investment, organizational capital (OC) is an important intangible resource that is normally not reported (Veneris et al. 2015). The costs associated with organizational development are mostly recorded in the sales, general, and administration (SG\&A) expense category. This includes information technology system costs, employee training, promotional brands, distribution channels, etc. (Lev et al. 2009). The financial impact of OC development affects the cost behavior and earnings performance of the company. Thus, it is necessary to analyze the company's cost behavior related to the financial impact of the organizational capital development.
This study uses an alternative model of cost asymmetry (Anderson et al. 2003) for which costs do not change mechanically linear to changes in company activity. Instead, they occur because of resource adjustment decisions deliberately made by management. Firms having more cost stickiness (CS) behaviors normally have a lower level of estimated earnings accuracy compared to firms lacking CS behaviors (Veneris et al. 2015). Accounting management literature has assumed that the CS phenomenon was typical management behavior. However, those studies did not consider the importance of intangible capital as a factor in managerial decisions related to commitment resource allocation and those impact on cost behavior patterns (Veneris et al. 2015). Therefore, for Indonesian firms, we measure the financial impact of the development of intangible investments per OC's level vs managerial behaviors per CS.

The CS level varies per nation, because firm characteristics, which are dependent upon national laws and regulations, determine the rates of adjustment costs on individual resources (e.g., asset intensity (AINT) and 
employee intensity (EINT)). Additionally, different countries show different optimistic/pessimistic trends associated with future economic growth (e.g., gross domestic product (GDP)). Managerial incentive (e.g., free cash flow (FCF)) differences can also impact adjustment decisions (Baumgarten 2012). This research extends that of Veneris et al. (2015) by analysing the relationships between OC, CS, and SG\&A. We use the annual financial reports of manufacturing companies listed in the Indonesian Stock Exchange and interim financial reports. We examine the levels of CS by using companies' quarterly financial report data to find specific fluctuations of management behavior within financial reporting periods. Then, we compare the information to levels of CS using annual financial statement data.

We expect that this study will provide results that differ from extant studies. Our study period was chosen to reflect economic fluctuations in Indonesia represented by GDP. These changes were assumed to affect the levels of demand and competition in the business environment, resulting in changes to management behavior and decision-making, especially in the manufacturing industry. Because the GDP after 2016 did not show a significant fluctuation, we assume that this research period represents cost behavior changes according economic levels.

Regarding the relationship between OC and SG\&A (Banker \& Byzalov 2015) stated that companies having high organizational levels would increase their remaining unused resources faster than companies having low organizational levels. This would, in turn, increase the level of CS. The increase of unused resources might be caused by the existence of high OC levels, increasing adjustment costs, and optimistic sales expectations. The purpose of this study is discover whether companies having high levels of OC will show a higher level of CS than companies having low OC levels and to discover whether the use of quarterly financial report data affects the reported levels of CS.

This research is useful to academics because it expand the understanding of Indonesian cost behaviors, including CS and OC, by looking at the financial and management interaction impact on changes in sales volume and corporate resource commitments. This research will be a useful reference for management regarding planning, cost controls, decision-making, capital-development and OC, and it will contribute to better control of excessive cost adjustments, especially considering the uncertainty of demand. For stakeholders, this study is beneficial because it will help them understand the firm's levels of CS and OC. It will also help them understand and evaluate management behaviors as they affect cost management for company development in OC. For investors, this information can be used as a reference to performance analysis of companies as the basis for investment decisions.

\section{LITERATURE REVIEW AND HYPOTHESIS DEVELOPMENT}

\subsection{Intellectual Capital}

Intellectual capital is a source of future economic benefits that have no physical form. These items are not always reflected in financial reports. Intellectual capital is often divided into categories, such as human capital, relational/consumer capital, and organization/structural capital (Veneris et al. 2015; CIMA 2003).

\section{2. $O C$}

OC is an important intangible asset that incorporates organizational structures and infrastructure technologies that facilitate the flow of knowledge, aiming to improve operational efficiency (Lev \& Radhakrishnan 2005). OC is a primary production factor unique for each company in the form of technological groupings, including business processes designs, incentives and compensation. It enables a company to consistently and efficiently optimally manage physical and human resources to generate abnormal income (above cost of capital), resulting in growth. It is useful to managers for tracking the size and growth of $\mathrm{OC}$ and comparing it with the OC level from previous periods and from competitors.

\subsection{OC Measurement}

Lev et al. (2009) estimated the economic value of OC by capitalizing and amortizing abnormal profits that characterized OC over a 5-year period. Although it seemed optimistic, the commitment portion of the SG\&A cost reflected the adjustment costs involved in changing business processes and enduring practices (Lev et al. 2009).

\subsection{Cost Behavior}

In the cost management literature, cost behavior has been a generic term describing the reaction to cost changes according to activity (output). During planning, managers should be able to anticipate cost behaviors that will occur when there are changes to an activity. These changes generally result in fixed, variable or mixed costs. (Garrison \& Brewer 2015; Hansen \& Guan 2009

\subsection{Traditional Cost Behavior Assumption}

Traditional cost behavior assumes that cost functions are mechanically linear. In practice, however, there are many nonlinear function costs, such those of price and 
production process efficiencies (Hansen \& Guan 2009). On the other hand, modern cost behaviors imply that managerial decisions are cost drivers (Garrison \& Brewer 2015). The most important conceptual basis of modern cost behavior is the view that costs arise from resource commitments made by managers (Banker et al. 2014).

\subsection{Modern Cost Behavior Assumption}

Over the past two decades, many studies have documented asymmetric cost behaviors over changes in activities where the amount of decrease in costs over the decrease in activity is lower than the amount of increase in costs when the activity increased. This is CS. This alternative model was introduced by Anderson et al. (2003) for SG\&A, where costs do not change mechanically per activity; they change according to management's resource adjustment decisions. Anderson et al. (2003) identified the causes of manager avoidance to reducing excessive resources when activities decreased. This led to asymmetric cost behaviors (Baumgarten 2012; Veneris et al. 2015).

In some cases, costs indicated anti-CS behaviors, occurring when the cost response to a decrease in activity level was greater than that if the activity increased (Balakrishnan et al. 2004). Literature has explained the phenomenon of costs stickiness using economic factors, such as adjustment costs, rates of change of economic activity, anticipation of future sales, and empire-building managerial behaviors.

\subsection{Framework $O C$ and $C S$}

Banker and Byzalov (2015) built a combined framework for CS, as shown in Graph I, Panel (A). It explains that when current sales (sales $t$ ) exceed the capacity of available resources, as described by the resources carried over from the previous period (resources $\mathrm{t}-1$ ), the company will proportionally increase resources (Panel A, Scenario A). When current sales fall, the company imposes maintenance costs on the remaining unused resources with adjustment costs associated with their reduction. At the intermediate sales level, unused capacity is positive but tends to be low. Then, the company maintains the initial resources level (Panel A, Scenario C). If the current level of sales drops far below the acceptable minimum capacity, the company will cut resources to reduce the remaining resources (Panel A, Scenario B). Two reasons are mentioned for this: adjustment cost and managerial expectations.

\section{CONTEXT OF EXPLANATION FRAMEWORK (BANKER \& BYZALOV 2015; VENERIS ET AL. 2015)}

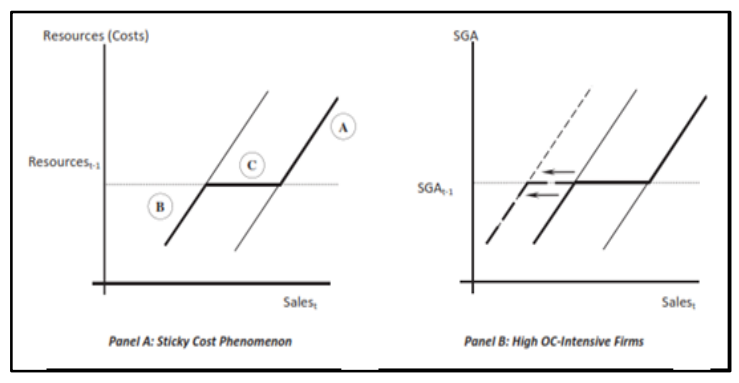

\subsection{Hypothesis}

This study aims to determine the level of CS in manufacturing companies having high and low levels of OC. The development of OC has a financial impact that will affect the cost behavior and earnings performance of the company. By rationalizing the relationship between OC and SG\&A cost behaviors in the context of the integrated framework explained by Banker and Byzalov (2015), when sales decrease, firms having high organizational levels will retain unused resources longer than firms having low organizational levels. Therefore, we arrive at the first hypothesis:

$\mathrm{H}_{0}$ : Companies having high organizational levels experience higher CS than companies having low organizational levels.

Anderson et al. (2003) and Baumgarten (2012) stated that levels of CS are influenced by the length of a study's observation period. The longer the observation period, the lower the CS. This is because the adjustment cost of one period will break even in future periods, and cost changes will become permanent. Thus, adjustment cost, one of the triggers of CS, will reduce. To test this idea, we recalculated CS level via the first hypothesis by using quarterly data rather than annual data to see if changes in financial statement data would result in changed CS levels. Thus, we arrive at our second hypothesis:

$\mathrm{H} 2_{0}$ : The use of quarterly observation data will affect the level of CS.

\section{RESEARCH METHOD}

This research is quantitative and uses a pooled data multiple regression model to analyze the influence of independent and control variables against the dependent variable. The purpose of this research is to understand the phenomenon of asymmetric behavioral costs (i.e., $\mathrm{CS}$ ) in manufacturing firms by considering the level of intangible investment through OC. The CS model is designed by using the following regression equation: 


\section{Basic Model}

$\mathrm{CS}_{\mathrm{it}}=b_{0}+b_{1} \mathrm{SC}_{\mathrm{it}}+b_{1} \mathrm{DD}_{\mathrm{it}} * \mathrm{SC}_{\mathrm{it}}+e_{i t}$.

\section{The Anderson, Banker, and Janakiraman (ABJ)}

\section{Model}

$$
\begin{aligned}
& \mathrm{CS}_{\mathrm{it}}=b_{0}+b_{1} \mathrm{SC}_{\mathrm{it}}+b_{2} \mathrm{DD}_{\mathrm{it}} * \mathrm{SC}_{\mathrm{it}}+b_{3} \mathrm{DD}_{\mathrm{it}} * \mathrm{SC}_{\mathrm{it}} \\
& * \mathrm{EINT}_{\mathrm{it}}+b_{4} \mathrm{DD}_{\mathrm{it}} * \mathrm{SC}_{\mathrm{it}} * \mathrm{AINT}_{\mathrm{it}}+b_{5} \mathrm{DD}_{\mathrm{it}} * \mathrm{SC}_{\mathrm{it}} \\
& * \mathrm{SD}_{\mathrm{it}}+b_{6} \mathrm{DD}_{\mathrm{it}} * \mathrm{SC}_{\mathrm{it}} * \mathrm{GDPt}+e_{i t} .
\end{aligned}
$$

\section{Extended Model}

$$
\begin{aligned}
& \mathrm{CS}_{\mathrm{it}}=b_{0}+b_{1} \mathrm{SC}_{\mathrm{it}}+b_{2} \mathrm{DD}_{\mathrm{it}} * \mathrm{SC}_{\mathrm{it}}+b_{3} \\
& \mathrm{DD}_{\mathrm{it}} * \mathrm{SC}_{\mathrm{it}} * \mathrm{EINT}_{\mathrm{it}}+b_{4} \mathrm{DD}_{\mathrm{it}} * \mathrm{SC}_{\mathrm{it}} * \mathrm{AINT}_{\mathrm{it}}+b_{5} \\
& \mathrm{DD}_{\mathrm{it}} * \mathrm{SC}_{\mathrm{it}} * \mathrm{SD}_{\mathrm{it}}+b_{6} \mathrm{DD}_{\mathrm{it}} * \mathrm{SC}_{\mathrm{it}} * \mathrm{GDP}_{\mathrm{t}}+b_{7} \\
& \mathrm{DD}_{\mathrm{it}} * \mathrm{SC}_{\mathrm{it}} * \mathrm{FCF}_{\mathrm{it}}+b_{8} \mathrm{EINT}_{\mathrm{it}}+b_{9} \mathrm{AINT}_{\mathrm{it}}+b_{10} \mathrm{SD}_{\mathrm{it}}+b_{11} \\
& \mathrm{GDP}_{\mathrm{t}}+b_{12} \mathrm{FCF}_{\mathrm{it}}+e_{i t} .
\end{aligned}
$$

$\mathrm{CS}_{\mathrm{it}}$ is the level of CS measured by the logarithm of changes in SG\&A costs during period t. $\beta_{0}$ is a constant intercept. $\mathrm{SC}_{\mathrm{it}}$ is the rate of change in annual net sales as measured by the logarithm of annual/quarterly sales changes. $\mathrm{DD}_{\mathrm{it}}$ represents the dummy interaction/moderation variable, which is worth 1 if net sales decreases during period $t$. Otherwise, it is 0 if annual net sales increase during period $t$, compared to the previous period (t-1). $\mathrm{SD}_{\text {it }}$ is the dummy interaction/moderation variable. It is worth 1 if net sales decreases for two consecutive periods. Otherwise, it is 0 . $\mathrm{AINT}_{\text {it }}$ represents the asset intensity of a company as measured by the total asset ratio logarithm to total net sales during period t. EINT it $_{\text {represets employee }}$ intensity owned by the company as measured by the logarithm ratio of the number of employees to the total net sales during period $\mathrm{t}$. $\mathrm{FCF}_{\mathrm{it}}$ is indicates the empire building incentives of management as measured by the ratio of free cash-flow during period t. $\mathrm{GDP}_{i t}$ is a control variable measured by the percentage change in economic growth rate during year t. b1, b2,..., b7 are independent variable coefficients and control variables. eit is the error coefficient.

The basic model use the main variables as the dependent variable and the independent variable of the annual log of changes of sales revenue $\left(\operatorname{Rev}_{\mathrm{it}}\right)$. Dummy variable $\left(\mathrm{d}_{\mathrm{it}}\right)$ is used to recognize the direction of change in company sales during year t. The b1 coefficient measures the increase's percentage in SG\&A costs per $1 \%$ increase in sales revenue. Alternatively, the value of $\mathrm{d}_{\mathrm{it}}$ is 0 when revenue increases. The coefficient of b2 measures CS and the sum of coefficients $b 1+b 2$ to measure the percentage of SG\&A cost reductions at a
$1 \%$ decrease of sales revenue. Alternatively, the value of $\mathrm{d}_{\mathrm{it}}$ is 1 when income decreases. The empirical hypothesis for CS states that $\mathrm{b} 1>0$ and $b 2<0$. Thus, $\mathrm{b} 1>\mathrm{b} 1+\mathrm{b} 2$.

In the ABJ model (Anderson, Banker, \& Janakiraman 2003), logarithms of the ratio of the number of employees $\left(\mathrm{Emp}_{\mathrm{it}}\right)$ to sales revenue $\left(\operatorname{Rev}_{\mathrm{it}}\right)$ and total assets $\left(\right.$ Asset $\left._{i t}\right)$ to sales revenue $\left(\operatorname{Rev}_{i t}\right)$ are used from company $i$ in year $t$ to measure the intensity of employees at a company and the intensity of assets. To capture the anticipated impact of future sales on the degree of stickiness, successive dummy variables are included $\left(\mathrm{ds}_{\mathrm{it}}\right)$, which take the value 1 if the company's sales revenue falls for two consecutive periods and 0 , otherwise. Additionally, to capture the impact of macroeconomic activity on the CS phenomenon, the $\mathrm{GDP}_{\mathrm{t}}$ variable is included, which is the percentage of actual GDP growth during year $t$.

In the extended model of Chen et al. (2012), expanding the ABJ model added free cash flow to the proxy for managerial empire-building incentives. Free cash flow is measured as cash flow from operating activities minus common and preferred dividends, multiplied by total assets.

To answer the first hypothesis, this study measures the level of $\mathrm{OC}$ in the sample data of companies by using the calculation of the contribution of OC (Lev et al. 2009). Then, the sample data is separated into groups of companies having the highest and lowest categories of OC based on the median of OC (quintile) to determine the more intensive OC. The level of CS was measured using ABJ model. Measurement of CS is performed for each group of companies according to a grouping of highest and lowest OC.

To answer the second hypothesis, the measurement of the CS is repeated using quarterly data from the yearly sample, leveraging the same OC grouping categories as with the first hypothesis testing. Moreover, we compare the CS of both data types to determine whether there are differences in cost behaviors during quarterly vs. annual periods.

\subsection{Data Sample}

This research step begins with a sample selection, based on criteria established by (Veneris et al. 2015). The period of research was taken from 2010-2016. This study was conducted using the data of financial statements of public companies obtained from Thomson-Reuters database and IDX.

From the total population, a sample of companies was analyzed to find the SG\&A expenses that were greater than sales revenues. Additionally, there we used a sample of companies where SG\&A expenses moved contrary to sales (Anderson \& Lanen 2009; Chen et al. 
2012). From a total sample of 22 companies over a period of 7 years, we retrieved 154 annual-data values and 616 quarterly-data values.

Table I. Sample Selection

\begin{tabular}{|l|l|c|}
\hline No. & \multicolumn{1}{|c|}{ Sample Selection Criteria } & Total Annual Data \\
\hline 1. & $\begin{array}{l}\text { Companies in the manufacturing industry sector which are listed } \\
\text { on the IDX until 2016 }\end{array}$ & 144 \\
\hline 2. & $\begin{array}{l}\text { Issue company observations that do not have positive SG\&A } \\
\text { revenues and costs and complete data }\end{array}$ & 38 \\
\hline 3. & $\begin{array}{l}\text { Issue company observations that have SG\&A costs greater than } \\
\text { sales revenue }\end{array}$ & 3 \\
\hline 4. & $\begin{array}{l}\text { Issues company observation that changes in SG\&A costs move } \\
\text { in the opposite direction to changes in revenue. }\end{array}$ & 81 \\
\hline \multicolumn{2}{|l|}{ Number of company samples } & $\mathbf{2 2}$ \\
\hline
\end{tabular}

\section{2. $O C$}

After sample selection, the research sample was grouped per OC level. The level of intangible investment was reflected in the level of OC measured through the financial impact of SG\&A expense because most of the financial impact of intangible investment development was included in SG\&A (Lev et al. 2009). For research purposes, the company in the sample data is grouped according to the contribution of $\mathrm{OC}$ Abnormal profit (AbProfit ${ }_{\mathrm{it}}$ ) was measured from period 5. Refer to Lev et al. (2009) for estimating the contributions of OC by combining the company's potential to generate more revenue and cost savings. Abnormal profit is the sum of abnormal sales that describes the contribution rate of OC on abnormal earnings of company $\left(\mathrm{AbSALE}_{\mathrm{it}}\right)$ and abnormal costs $\left(\mathrm{AbCOST}_{\mathrm{it}}\right)$, as described by cost containment.

$$
O C_{i, t}=\frac{\sum_{4}^{k=0}(1-0,2 k) \text { AbProfit }}{i, t-k}
$$

$$
\text { AbProfiti,t. = AbSALEi, }, \mathrm{AbCOSTi,t} \text {. }
$$

Abnormal sales $\left(\mathrm{AbSALE}_{\mathrm{it}}\right)$ are derived from the annual income difference vs. revenue forecasts as a function of SG\&A cost, which are amortized over 3 years, number of employees, and net fixed assets. $\mathrm{AbSALE}_{\mathrm{it}}$ of firm $\mathrm{i}$ during year $\mathrm{t}$ is the difference between actual company earnings and predicted earnings according to average efficiency without OC. The predicted income in the model as a function of the company's output of physical capital and labor. The earnings model coefficient was obtained by estimating an equation model in which SG\&A.CAP it is calculated by capitalizing and amortizing the annual SG\&A expense after 3 years, assuming the useful life of intangible investment is exhausted within 3 years. Then, we used the coefficient estimate of the income prediction model, as calculated by the monetary form of the OC contribution to the income. By reducing the company's predictive revenue without OC from actual company earnings, we can generate $\mathrm{AbSALE}_{\mathrm{it}}$, which is the contribution of $\mathrm{OC}$ to revenue from company $\mathrm{i}$ during year $\mathrm{t}$.
Abnormal Cost $\left(\mathrm{AbCOST}_{\mathrm{it}}\right)$ is also calculated from the contribution of $\mathrm{OC}$ to the cost of containment by measuring the cost prediction of industry averages of resources utilized to generate sales. $\mathrm{AbCOST}_{\text {it }}$ is OC's contribution to cost containment (Lev et al. 2009). $\mathrm{AbCOST}_{i t}$ is the difference between actual and predicted costs according to average efficiency without OC. It is calculated similarly to $\mathrm{AbSALE}_{\mathrm{it}}$, but is replaced using operating costs. The prediction of operating cost is taken from the same income function by replacing the annual income with operating costs.

Subsequently, the company is ranked and classified into subgroups based on the OC level, using the $\mathrm{MOC}_{\mathrm{it}}$ variable, which is the median value of the $\mathrm{OC}_{\mathrm{it}}$ variable of the firm. The $\mathrm{MOC}_{\mathrm{it}}$ calculation is based on the $\mathrm{OC}_{\mathrm{it}}$ variable, which is the measurement of the output of the OC, because it is an abnormal profit accumulation from the current year and the preceding 4 years, considering the consumption of resources for its development (measured as the capitalization rate of SG\&A expense for 3 years).

We repeat the test using the rank and classification of the company samples using the $\mathrm{MOAC}_{\mathrm{it}}$ variable, which is the median value of the adjusted $\mathrm{OC}\left(\mathrm{AOC}_{\mathrm{it}}\right)$ of the firm. $\mathrm{AOC}_{\mathrm{it}}$ is calculated the same as $\mathrm{MOC}_{\mathrm{it}}$, but is modified by the issuing advertising expense from SG\&A_CAP ${ }_{\text {it. }}$ This is because of advertising expenses related to the relationship of the company with the customer, which has the least relationship with the development of OC of the company. Calculation of A.SG\&A_CAP it $_{\text {, }}$ representing the annual adjusted SG\&A expense via capitalization and amortization for 3 years, where A.SG\&A $A_{i t}$ is the annual SG\&A expense minus advertising exp $\left(\mathrm{AE}_{\mathrm{it}}\right)$. The grouping of firms is selected by taking the highest and lowest quartiles of the median and from the quintiles over the sample level of OC firm to better test the specific samples, both on OC and adjusted OC.

\section{RESULT AND DISCUSSION}

Based on the calculation of OC, samples were rank and classified as follows. There were 77 (77) OC variables based on the median grouping of MOC (MAOC), taken from variables there are 77 (77) annual observation data of both high and low categories. However, from quarterly observation data, there were 292 (296) low and 302 (298) high. However, the quintile group of MOC MAOC) was 30 (30) low and 31 (31) high, whereas, from the quarterly observation data, there were 114 (113) low and 120 (120) high.

After OC ranking and classification, all sample data were used to measure the level of CS from three CS Models (Veneris et al. 2015). Then, all data were used for the regression test to answer the hypotheses, as shown in Tables II and III. 
Table II. Regression Test with Annual Data

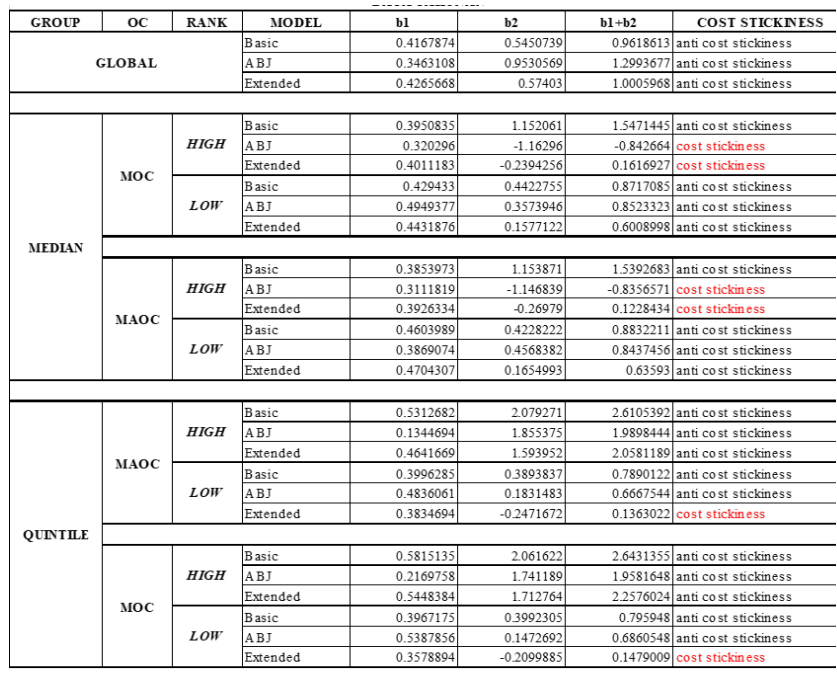

Table II shows that, in the median group, companies having a high level of OC showed higher levels of CS compared to companies having low levels of OC. The results of this study are in line with the research of Veneris et al. (2015). Thus, in companies having a high OC level, managers tended to maintain resources related to the development of $\mathrm{OC}$ under conditions of decreased sales. The managers considered the costs of developing $\mathrm{OC}$ as an investment with long-term benefit, provided it were to be carried out aggressively over a period of decline in sales. Then, it would cause a decrease in profit for the current period and possibly during a period of increased sales. The manager must, therefore, incur greater costs for resource recovery than for maintenance over declining sales. This can cause an increase in the burden on resources maintained over a short-term period. However, it will be beneficial over the long term.

Additional pre-grouping tests on quintile data were conducted to determine the consistency of results based on the median group. After testing global data and quintile groups, results showed that, for companies having either high or low OC, both showed antistickiness cost asymmetry behavior. This is because of the conditions of the trend of sales changes, which was a proxy of changes in the activities of manufacturing companies. Most, in fact, experienced an increase. This condition provides a different result than previous research and contradicts to the basic CS model that focuses on decreasing company activity (decreasing dummy).

This anti-CS condition reflects the tendency of pessimistic management behaviors towards future demands in accordance with the assumptions of Baker and Byzalov (2015), which stated that managers aggressively cut unused resources during a period of sales decline, because they consider the decline to be permanent and expect resources to remain unused. This, in turn, reduces $\mathrm{CS}$ or increases anti-CS. These conditions imply that managerial decisions are controlled by incentives, according to Kama and Weiss (2013). To avoid losing profits or to achieve profit targets, managers tend to adjust resources faster when activity levels decrease than when activities increase.

Judging from the coefficient value of the level of $\mathrm{CS}$, the results of this study indicate that, for both quintile and median groups the value of the CS or antistickiness in the High-OC category was higher than the level of anti-stickiness in the Low-OC category. Additionally, the difference in the level of CS or antiCS between the MOC and MAOC classifications differed little between the quintile and median groups and High and Low OC. This shows that the influence of advertising expenses on the level of contribution of OC based on SG\&A cost was not very large.

Table III. Reegression Test with Quarterly Data

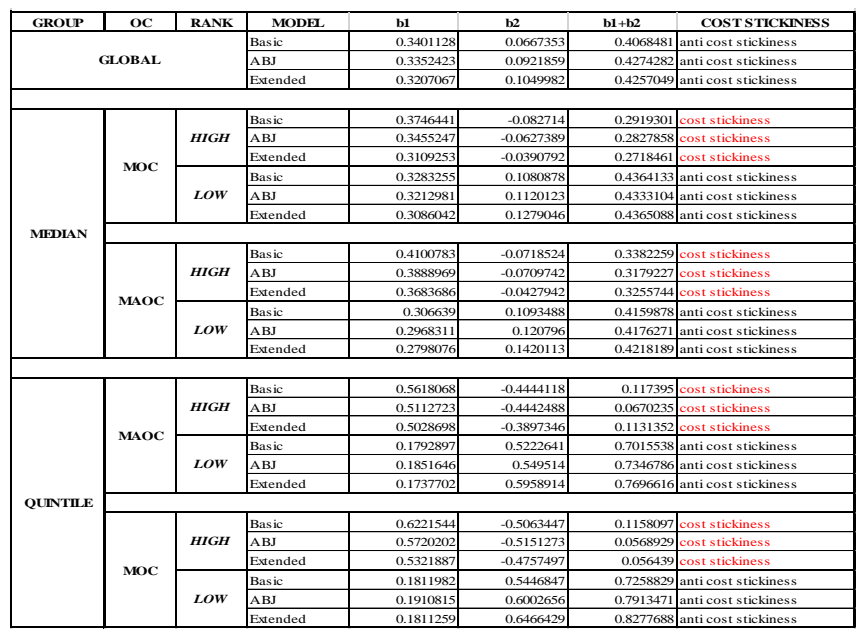

Table III shows that, in both the median and quintile groups, companies having high OC levels showed higher levels of CS compared. This shows that our results are in line with the research of Veneris et al. (2015).

If we compare the measurements of CS between annual and quarterly financial statement data, we find that, in the global data group, both results support antiCS. However, the quarterly data showed a lower coefficient level. In the median group, the CS measurement from annual data supported anti-CS in the basic ABJ, and extended models. Meanwhile, measurements using quarterly data showed results supporting CS in all three models. The levels of CS also showed a lower coefficient on the quarterly measurement results. In the quintile group, the results of CS measurements using annual data showed results that supported anti-CS, whereas the quarterly data showed results supporting CS.

Based on the results above, it is can be concluded that, in line with $\mathrm{H} 2{ }_{0}$, the use of quarterly data affects 
the level of CS. In accordance with the assumptions of Anderson et al. (2003) and Baumgarten (2012), observations taken over a longer period will show a lower level of CS. This is because the longer the period of consistency, the decrease in demand becomes more certain and the adjustment decisions become more precise. Additionally, the adjustment costs made in one period will break even in the next period, so that changes in costs will be permanent.

\section{CONCLUSION AND IMPLICATION}

Using global samples, manufacturing companies in Indonesia showed predominately anti-cost stickiness behaviors. During the study period, the number of sample companies that increased sales out numbered those that decreased. However, the rate of SG\&A changes tended to be more sensitive to the increase of sales than their decline. For both annual and quarterly data, companies having High OC showed higher CS than those having Low-OC. Therefore, we can conclude that $\mathrm{H}_{0}$ is accepted. As shown in Tables II and III, we can also conclude that using quarterly data changed the measured level of CS. Therefore, $\mathrm{H} 2_{0}$ is also accepted.

Market demand uncertainty influenced changes in firms' sales rates, affecting manager behavior regarding resource commitments and cost behavior. The process of identifying behaviors and cost structure refers to how costs change with changes in activity levels. Aggressive management behaviors (e.g., cutting off unused residual resources during a declining sales period) reflect a pessimistic view of the increase in sales demand for the future period. They may also be caused by managerial decisions influenced by incentive management.

Adjustment costs that cause CS because of the development of capital results in high loading during a period of sales decline. This can ultimately suppress profit performance. To maintain performance, the company can make cost reductions on several cost items to cover the impacts of managerial behavior (e.g., SG\&A efficiency, depreciation management, and amortization). They can make policies of asset capitalization, such that loading during one period does not exceed revenue sales results. The determination of the limits on loading value can employ a standard used by competitors or in similar industries to avoid overspending or underspending during a financial statement period.

\section{RESEARCH LIMITATIONS}

Our research model focused primarily on the conditions of declining income trends using a decrease dummy while combining the conditions of increasing and stable income trends. This research did not test the cost stickiness per changes in the level of sales. Thus, we cannot determine how the level in sales changes influence CS. The cost categories tested in this study were limited to SG\&A. The samples were limited to the manufacturing industry and may not be generalizable.

Further research should test a broader range of data for stronger test results. The selection of the study period should consider the economic conditions of the period in question. Further research should measure the levels of sensitivity of the CS by testing the stickiness of the group according to different sales changes. Future research is expected to test other cost categories, such as operating expense, cost-of-goods sold, etc., including other industries. Companies ought to consider CS information based on management decision-making related intangible investments. Measuring the level of OC can help managers measure the contribution rates of intangible investments.

\section{REFERENCES}

[1] Anderson, MC, Banker, RD \& Janakiraman, SN 2003, "Are Selling, General and Administrative Costs 'Sticky'?" Journal of Accounting Research, vol. 41, pp.47-63.

[2] Anderson, SW \& Lanen, WN 2009, "Understanding Cost Management: What Can We Learn from the Empirical Evidence on 'Sticky Costs'?" Working Paper. http://papers. ssrn.com/sol3/papers. cfm?abstract_id=975135.

[3] Balakrishnan, R, Peterson, MJ \& Soderstrom, NS 2004, "Does Capacity utilization affect the stickiness of cost?" Journal of Accounting and Auditing Finance, vol. 19, pp.283-299.

[4] Banker, RD, Byzalov, D, Ciftci, M \& Mashruwala, R 2014, "The moderating effect of prior sales changes on asymmetric cost behavior," Journal of Management Accounting Research.

[5] Banker, RD \& Byzalov, D 2015, “Asymmetric cost behavior." Journal of Management Accounting Research, http://aaajournals.org/toc/jmar/0/0, (forthcoming).

[6] Baumgarten, D 2012, "The Cost Stickiness Phenomenon: Causes, Characteristics, and Implications for Fundamental Analysis and Financial Analysts' Forecasts," Germany: University of Cologne. Dissertation. Springer Fachmedien Wiesbade

[7] Chen, CX, Lu, H \& Sougiannis, T 2012, "The Agency Problem, Corporate Governance, and the Asymmetrical Behavior of Selling, General, and Administrative Costs," Contemporary Accounting Research, vol. 29, pp.252-282. 
[8] CIMA 2003, Understanding Corporate Value: Managing and Reporting Intellectual Capital. Cranfield University.

[9] Datastream. (2017) Thomson Reuters Datastream. [Online]. Available at: Subscription Service (Accessed: November 2017)

[10] Garrison, N \& Brewer 2015, Managerial Accounting, $15^{\text {th }}$ Ed. McGraw-Hill Education.

[11] Hansen, M \& Guan, L 2009, Cost Management: Accounting and Control, $6^{\text {th }} \mathrm{Ed}$., South-Western

[12] Kama, I \& Weiss, D 2013, "Do Earnings Targets And Managerial Incentives Affect Sticky Costs?" Journal of Accounting Research, Vol. 51, pp.201224.
[13] Lev, B \& Radhakrishnan, S 2005, The Valuation of Organization Capital. University of Chicago Press, pp.73-110.

[14] Lev, B, Radhakrishnan, S \& Zhang, W 2009, “Organization Capital," Abacus, vol. 45, pp.275298.

[15] Miyagawa, T \& Kim, Y 2008, "Measuring Organizational Capital in Japan: An Empirical Assessment Using Firm-Level Data," Seoul Journal of Economics, vol. 21. No. 1.

[16] Veneris, G, Naoum, VC \& Orestes V 2015, "Organisation Capital and Sticky Cost Behavior of Selling, General, and Administrative Expenses," Management Accounting Research, vol. 26, pp.5482. 